\title{
Cultura Brasileira e autoritarismo em Nelson Werneck Sodré
}

\author{
Eduardo Russo Ramos ${ }^{1}$
}

\begin{abstract}
RESUMO
O presente artigo realiza uma aproximação ao pensamento do historiador, crítico literário e militar carioca Nelson Werneck Sodré através do exame de duas obras que marcaram suas intervenções no plano político-intelectual da ditadura civil-militar instalada pelo golpe de 1964: Síntese de História da Cultura Brasileira, publicada em 1970, e Vida e Morte da Ditadura: 20 anos de autoritarismo no Brasil, publicada em 1984. Inserindo-se no âmbito de uma pesquisa acerca do itinerário formativo de Sodré enquanto um dos primeiros intelectuais da tradição marxista brasileira, este trabalho busca compreender sua percepção sobre os impactos da ditadura na sociedade brasileira, especialmente no âmbito da cultura. Portanto, o objetivo de nosso estudo é apresentar e analisar as teses sustentadas pelo autor na formação dos debates sobre cultura e autoritarismo no Brasil, compreendendo assim a discussão sobre o papel, produção e circulação da cultura na luta antiditatorial e a inserção do intelectual neste plano. Seguese, assim, tanto uma reflexão sobre a obra sodreana quanto um resgate das contribuições deste teórico que sofreu e sofre um ostracismo na academia brasileira desde a década de 80 .
\end{abstract}

Palavras-Chave: Pensamento social brasileiro; Tradição marxista brasileira; Nelson Werneck Sodré; Cultura brasileira; Autoritarismo.

Mestrando pelo Programa de Pós-Graduação em Sociologia da Universidade Federal do Paraná (UFPR), contemplado com bolsa do Programa de Demanda Social da CAPES. E-mail: ramos.eduardorusso@gmail.com 
No ano de 1985, Nelson Werneck Sodré publicou um artigo intitulado $A$ Cultura e a Democracia no Jornal do País, periódico sediado na cidade do Rio de Janeiro, e, na forma de um breve comentário sobre o estado da cultura brasileira naquele momento de transição, argumentava que: "As pessoas que viveram períodos anteriores à ditadura e as que conhecem alguma coisa da história tiveram condições de avaliar os prejuízos que a ausência de democracia trouxe ao nosso desenvolvimento cultural." (SODRÉ; ALVES FILHO, 1998, p. 84). Na perspectiva sodreana, a relação entre democracia e cultura era tão íntima que "defender a democracia é o mesmo que defender a cultura e vice-versa." (Ibid, p. 84-85).

O presente artigo faz parte de uma pesquisa em desenvolvimento acerca do pensamento social produzido pelo historiador e crítico literário Nelson Werneck Sodré, cuja investigação está voltada para compreender sua formação enquanto pioneiro intelectual marxista e suas contribuições para o desenvolvimento da tradição marxista no Brasil.

Ao tomar a obra de Sodré como objeto de estudo é necessário destacar que, como já salientaram alguns de seus analistas, esta obra foi alvo, dos anos 70 em diante, de uma repetida desqualificação e de um ostracismo que não propiciou um debate profícuo e aprofundado de suas teses, de sua interpretação do Brasil (NETTO, 1992, p. 26; KONDER, 1991, p. 78; CÔRTES, 2011, p. 310). Esse fenômeno foi bem descrito pelas palavras de José Paulo Netto:

O fato é que, nos quintais universitários, Sodré e sua obra são sumariamente fuzilados como "ortodoxos", "esquemáticos", "mecanicistas" - sem que se conheçam estudos rigorosos que se ocupem da comprovação de tão inapeláveis julgamentos. Na verdade, o que se vem construindo em torno da obra de Sodré, nos últimos três lustros, é uma muralha de preconceitos que assombra: tanto menos se a examina com os cuidados habituais da crítica séria, tanto mais se difundem juízos que a desqualificam (1992, p. 27). 
Neste plano, ressalve-se o fato de que nos anos que se seguiram ao falecimento de Sodré houve uma tentativa sólida de resgate e debate de sua obra expressa nas seguintes obras: Nelson Werneck Sodré na historiografia brasileira, ${ }^{2}$ coletânea de artigos organizada pelo pesquisador Marcos Silva, publicada em 2001; Um olhar à esquerda: a utopia tenentista na construção do pensamento marxista de Nelson Werneck Sodré, 3 do pesquisador Paulo Ribeiro da Cunha, publicada em 2002; Nelson Werneck Sodré: entre o sabre e a pena, ${ }^{4}$ coletânea de artigos organizada pelos pesquisadores Paulo Ribeiro de Cunha e Fátima Cabral, publicado em 2006; Dicionário crítico Nelson Werneck Sodré, ${ }^{5}$ também de Marcos Silva, publicado em 2008; entre outras séries de artigos, dissertações e teses que vem buscando compreender a obra e a formação de Sodré.

Entretanto, ressalve-se também que, apesar desta grande iniciativa, não se instalou um debate acadêmico generalizado acerca do legado de Sodré, não tendo havido reedição ou reimpressão de suas obras principais nem sequer a realização de seminários voltados para este debate. Ainda neste plano, destaque-se também que, do pouco debate que existe, este orbita em torno das polêmicas sobre a tese do feudalismo no Brasil entre Sodré e seus interlocutores, como Caio Prado Júnior e Jacob Gorender, havendo uma verdadeira marginalização da extensa produção do autor sobre a cultura brasileira, a literatura, a interpretação dos principais eventos políticos da

\footnotetext{
2 SILVA, Marcos (org.). Nelson Werneck Sodré na historiografia brasileira. Bauru: EDUSC; São Paulo: FAPESP, 2001.

3 CUNHA, Paulo Ribeiro da. Um olhar à esquerda: a utopia tenentista da construção do pensamento marxista de Nelson Werneck Sodré. 2. ed. Rio de Janeiro: Revan, 2011.

4 CUNHA, Paulo Ribeiro da; CABRAL, Fátima (orgs.). Nelson Werneck Sodré: entre o sabre e a pena. 2. ed. São Paulo: UNESP, 2011.

5 SILVA, Marcos (org.). Dicionário crítico Nelson Werneck Sodré. Rio de Janeiro: UFRJ, 2008.
} 
história nacional no século XX, assim como suas contribuições no campo teórico voltadas para a historiografia marxista.

Assim, levando em conta tal condição do debate e tendo como objetivo deste artigo uma aproximação ao pensamento social sodreano, nada seria mais adequado do que realizar uma breve introdução do leitor à sua biografia.

Nelson Werneck Sodré, nascido no Rio de Janeiro, no dia 27 de abril de 1911, filho único do advogado Heitor de Abreu Sodré e Amélia Werneck Sodré, foi "uma das figuras mais importantes da cultura brasileira do século XX" (NETTO, 2011, p. 10). Apresentando desde cedo grande interesse e vocação pelas letras, aos 13 anos, ingressando no Colégio Militar do Rio de Janeiro, começa a colaborar com textos de ficção para a revista $A$ aspiração, pertencente à sociedade literária da instituição (Ibidem, p. 15). Já aos 18 anos, estreia sua participação na imprensa com o conto "Satânia", premiado e publicado na revista carioca O Cruzeiro (Idem). Em 1931, completando 20 anos, ingressa na Escola Militar de Realengo, optando pela artilharia, e esse momento marca o início de uma trajetória pessoal que combinará ao longo de sua vida a vocação intelectual com a vocação militar (Ibidem, p. 14). Nos anos que se seguem ao início dessa formação na oficialidade do Exército, Sodré continua sua colaboração na imprensa e produz sua primeira obra, História da literatura brasileira: seus fundamentos econômicos, publicada no ano de 1938, que, conforme a análise realizada por Netto, seu caráter pioneiro no âmbito de uma abordagem global da nossa história literária numa perspectiva marxista e a interpretação do Brasil ali inscrita - mesmo que ainda de caráter incipiente e que será depois revisado pelo próprio autor na década de 60 -, assegura o lugar de Sodré ao lado de outros intérpretes do Brasil no período, como Caio Prado Júnior, Gilberto Freyre e Sergio Buarque de Holanda (1992, p. 37). 
Entre tantos deslocamentos e transferências realizadas por conta da carreira militar, Sodré estreita os laços com os meios intelectuais e passa a colaborar tanto com a imprensa paulista quanto com a carioca. Neste período, integrou a chapa vitoriosa da eleição de 1950 para a direção do Clube Militar - chapa nacionalista que encabeçava a campanha $O$ petróleo é nosso - e assumiu a Direção Cultural do Clube. Como indica Netto, os desdobramentos desse período contribuíram de forma significativa para a definição do perfil político e intelectual de Sodré (2011, p. 17).

Alvo da perseguição da chapa vencida, Sodré é transferido em 1951 para uma unidade militar do Rio Grande do Sul de onde só retornaria no ano de 1955, que marca também seu ingresso nas cadeiras do Instituto Superior de Estudos Brasileiros, o ISEB. Marcando um momento de intenso engajamento político-intelectual, é neste período que Sodré produzirá boa parte de suas intervenções mais significativas no campo da historiografia e da tradição marxista brasileira. Como destaca Netto:

(...) no Iseb, Sodré encontrou, num ambiente de estudos e pesquisas, condições para avançar em suas formulações e em seu magistério, interagindo com pensadores de posições teóricas e ideológicas muito diferenciadas e com um público com o qual ele nunca contactara antes. Se já era um intelectual respeitado quando o convidaram para atuar no Iseb, parece-nos que é ali que alcançará (na altura em que chegava aos seus 50 anos) a maturidade teórica que lhe permitirá conquistar a indiscutível audiência nacional que sua obra obterá na década de 1960 (Ibidem, p. 35-36).

Aproximando-se de 1964, Sodré, que já se encontra na reserva como General de Brigada, produz a obra coletiva História Nova, fruto de um trabalho realizado com estagiários escolhidos das cadeiras da Faculdade Nacional de Filosofia (FNFi), sua última contribuição enquanto professor do ISEB. A coleção representava uma crítica da historiografia tradicional mediante a realização de pesquisas monográficas voltadas para o ensino da história no Ensino Médio como alternativas aos compêndios didáticos do período (MENDONÇA, 2011, p. 335-337). Considerada "subversiva”, foi apreendida 
nas livrarias logo após o golpe civil-militar de 1964, seu projeto editorial foi suspenso e instaurado um Inquérito Policial-Militar para investigar as ações subversivas de seus autores (CZAJKA, 2012, p. 301).

O golpe civil-militar marca ainda a extinção e depredação do ISEB, a perseguição e prisão de seus professores, estagiários e estudantes, inclusive Sodré (PEREIRA, 2005, p. 259-260). Do impacto do golpe no seio das esquerdas e dos movimentos sociais, é importante destacar com Rodrigo Czajka, que este produziu uma rearticulação das tendências políticas e ideológicas de esquerda em torno de um novo objetivo: “o restabelecimento do processo democrático." (CZAJKA, 2014, p. 103-104). Intelectual de envergadura, engajado e militante, Sodré não passará ao largo deste processo.

Como destaca Cunha:

\begin{abstract}
Na fase subsequente ao golpe militar, sua intervenção política e teórica continuou de várias formas, mas foi particularmente intensa e aguda após o advento do AI-5, em 1968, quando o autor continuou escrevendo artigos (muitas vezes sob pseudônimo) e livros, procurando intervir de várias maneiras na luta pelo restabelecimento da democracia; e, ao longo daqueles anos, Sodré foi uma referência ao radicalismo e ao aventureirismo pequenoburguês que caracterizavam as iniciativas armadas de parcelas da esquerda brasileira na luta contra a ditadura militar. Foi igualmente um período de quase ostracismo em alguns importantes círculos acadêmicos, embora, como autor, tivesse, nesta fase, singular e profícua produção teórica (2011a, p. 100).
\end{abstract}

Intelectual irrefreável, nos últimos anos de vida Sodré continuou produzindo e contribuindo com a imprensa. No ano de 1995, publica sua última obra, A farsa do neoliberalismo. Falecido em janeiro de 1999, autor de 56 livros e de cerca de três mil artigos, o itinerário da formação intelectual de Sodré retrata a trajetória de um intelectual engajado com as lutas de seu tempo, dotado de uma profunda capacidade crítica (e autocrítica, basta ver as anotações apontadas por Netto acerca das revisões e correções que o autor realizou em suas obras ao longo da vida (1992, passim)) e uma das 
figuras mais relevantes no processo de desenvolvimento de nossa tradição marxista.

Delineadas estas questões propedêuticas para a análise da obra sodreana, o presente trabalho também tem como objetivo analisar duas obras do autor, situadas no período posterior ao impacto do golpe-civil militar em sua trajetória. Tratam-se das obras Síntese de História da Cultura Brasileira, ${ }^{6}$ de 1970, e Vida e Morte da Ditadura: 20 anos de autoritarismo no Brasil, ${ }^{7}$ de 1984. É necessário, entretanto, definir o tom de tal análise.

Tendo em vista a relação estabelecida entre cultura e democracia pelo autor no artigo supracitado de 1985 , buscamos aqui investigar se há algum desenvolvimento mais complexo desta relação nestas obras. A seleção dos títulos está relacionada com os temas trabalhados: um tendo como centro a cultura brasileira e outro o autoritarismo.

Observando a questão da condição do debate acerca da obra do autor e a incipiência de nossa pesquisa, cumpre fixar aqui que há neste trabalho um esforço de clarificação acerca dos debates realizados por Sodré, os conceitos, teses e temas mobilizados na análise sodreana, seus interlocutores e demais fatores que envolvem a apreciação de sua produção intelectual. Portanto, neste plano, não pretendemos realizar aqui uma análise exaustiva, sistemática e comparativa das teses sodreanas tendo em vista que, para tanto, seria necessário apreciar uma série de fenômenos de natureza histórica e social (para citar alguns, imperialismo, guerra fria, organização militar, democracia no Brasil, revolução burguesa no Brasil, etc.) e ainda

$6 \quad$ SODRÉ, Nelson Werneck. Síntese de História da Cultura Brasileira. 7. ed. Rio de Janeiro: Civilização Brasileira, 1979.

7 SODRÉ, Nelson Werneck. Vida e Morte da Ditadura: Vinte anos de autoritarismo no Brasil. Petrópolis: Vozes, 1984. 
cotejá-los com o debate coetâneo à publicação das obras, o que, obviamente não pode ser comportado em um trabalho desta natureza.

Por fim, antes de prosseguirmos à análise, cumpre ainda salientarmos duas questões cruciais e problemáticas do estudo da obra sodreana. A primeira é a questão da relação do autor com o Partido Comunista Brasileiro, no caso, mais especificamente, com as teses do PCB. Tratando-se ainda de um tema pouco explorado, há uma divergência muito grande entre os analistas da obra de Sodré. À título de ilustração desta divergência, basta constarmos que, enquanto Caio Navarro de Toledo defende que em Sodré há uma defesa intransigente da linha política do PCB (TOLEDO, 2001, p. 53), Cunha argumenta que "vincular as teses de Sodré às teses que se vinculam ao PCB é um equívoco." (2011a, p. 91). Portanto, dada a complexidade desta relação, não analisaremos aqui a congruência ou incongruência das teses endossadas por Sodré nas obras indicadas com as teses do PCB, com sua linha política e cultural no contexto da ditadura.

A segunda questão, trata-se do problema da ausência de formação acadêmica na trajetória de nosso autor. Qualquer leitura da obra de Sodré se depara com a ausência da citação de suas fontes e isso é um fator problemático para qualquer trabalho que busque situar a obra de Sodré em relação aos seus interlocutores, desvendando seus embates teóricos, proximidade ou não em relação à determinados meios intelectuais, correntes teóricas e até mesmo em relação ao problema anterior, as teses do PCB. Ressalte-se ainda dois fatores significativos para compreensão deste problema. Além de Sodré apresentar uma formação autodidata, vale destacar que esta formação se dá num período em que ainda não há uma profissionalização da vida intelectual nos limites das instituições universitárias, fenômeno estudado por Russel Jacoby (JACOBY, 1990), e debatido por Marcelo Ridenti em sua análise da vida intelectual brasileira no contexto dos anos 6o e 70 (RIDENTI, 2003, p. 206-209). 
$\mathrm{O}$ outro fator envolve tanto o pioneirismo do historiador quanto o traço distintivo de suas análises. Situando o autor em seu tempo, Netto demonstra a importância de seu esforço teórico e crítico-analítico considerando o cenário intelectual de sua formação:

\begin{abstract}
A tradição marxista brasileira possuía poucos suportes a oferecer a Sodré - apenas um outro intelectual a ela vinculado, Caio Prado Jr., lavrara especificamente a seara da história, mas suas ricas contribuições tinham uma abrangência muito menor que os interesses de Sodré. Na verdade, é justamente neste momento - o final dos anos cinquenta - que, liberando-se a duras penas do dogmatismo próprio do marxismo oficializado pela autocracia stalinista, a tradição marxista começa a florescer no país, e a obra de Sodré é componente axial deste florescimento (1992, p. 26).
\end{abstract}

Combinado ao pioneirismo, Netto ainda ressalta o tratamento privilegiado que Sodré concede à literatura e sua "extrema sensibilidade em face dos fenômenos ideais" (1992, p. 30-31). De acordo com o autor, esta sensibilidade à expressões políticas, sociais e culturais imantou os interesses de Sodré e recebeu dele abordagens cuidadosas e esclarecedoras (Ibidem, p. 31). Assim, nos parece adequado compreender a ausência de fontes nas obras em conexão com tais fatores - pioneirismo, tratamento da cultura numa perspectiva marxista dentro do cenário intelectual brasileiro de seu tempo e a ausência de formação acadêmica - e, desta forma, identificar uma verdadeira dificuldade no trabalho analítico voltado para a elucidação do pensamento social sodreano.

Sem mais demoras, prosseguiremos à exposição das obras indicadas, assinalando seus principais tópicos, desenvolvimento conceitual e eventuais interlocutores identificados.

\title{
Desenvolvimento cultural, cultura transplantada e democracia
}

Publicada num dos períodos mais rigorosos da ditadura militar, a obra Síntese de História da Cultura Brasileira, de 1970, é, como destacou Cristiano Alencar Arrais, "uma das primeiras tentativas de explicação global da 
formação da cultura brasileira ao longo de quase quinhentos anos de influência de culturas estrangeiras." (ARRAIS, 2008, p. 392).

A obra é dividia em duas partes, $A$ herança cultural e $O$ desenvolvimento cultural, onde o autor trabalha uma série de questões a partir de seu conceito de "cultura transplantada", ${ }^{8}$ que, como Netto destaca, já havia sido elaborado na obra $A$ ideologia do colonialismo, de 1961 (2011, p. 58-59). Assim, a primeira parte se destina a discutir o desenvolvimento cultural brasileiro a partir da compreensão de sua origem colonial (SODRÉ, 1979, p. 4), da heterogeneidade de cada cultura que compõe o cenário colonial (a indígena, a africana e a portuguesa) (Ibidem, p. 5), o traço de classe da cultura transplantada e o desenvolvimento histórico da cultura no território nacional considerando o desenvolvimento socioeconômico da sociedade brasileira ao longo de sua história (o autor tematiza, neste sentido, as relações de produção pré-capitalistas, a estrutura da nossa sociedade de classes, o desenvolvimento das relações capitalistas ao longo do século XIX e XX, o surgimento de uma cultura propriamente nacional). Já a segunda parte da obra, o autor apresenta uma discussão acerca do impacto do desenvolvimento das relações capitalistas no âmbito da produção cultural (Ibidem, p. 63), abordando fenômenos como a transformação dos produtos da cultura em mercadoria, a "massificação cultural" (Ibidem, p. 64-78) e seus reflexos na organização e difusão da cultura. Neste âmbito, o autor realiza uma análise extensa sobre a produção cultural do período, avaliando a situação do cinema, do rádio, da televisão, da música, do teatro, das artes plásticas, da Universidade, da imprensa e do livro (Ibidem, p. 79-134).

\footnotetext{
8 Trata-se de fenômeno associado à transplantação da "civilização" portuguesa para o território brasileiro, que carrega consigo os elementos necessários para a produção e o comércio e, com isso, um conjunto de formas culturais heterogêneas. Cf. SODRÉ, Nelson Werneck. Síntese..., p. 3-9.
} 
É interessante destacar que, na parte de discussão propriamente teórica e histórica, o autor dialoga principalmente com a obra A cultura brasileira: introdução ao estudo da cultura no Brasil, de 1943, de Fernando de Azevedo, dedicando também notas a Sergio Buarque de Holanda, Luís Carlos Bonfim, Sidney Finkelstein, Jaime Rodrigues, Paul Lazarsfeld, Nelson Lontra e Sergio Bittencourt. Em sua análise também consta a leitura das obras disponíveis em uma edição francesa das obras completas de Karl Marx, Friedrich Engels, e uma citação à obra Teatro dialético, de Bertolt Brecht.

No que tange à sua análise da cultura brasileira, é interessante a distinção que o autor realiza em relação à cultura transplantada e cultura alienada. Para Sodré, enquanto a primeira é etapa necessária do processo de colonização do território (Ibidem, p. 11), a segunda é fator que acrescenta à transplantação uma dimensão nova (Ibidem, p. 15). O caso que exemplifica esta distinção é o desenvolvimento do ensino jesuítico no panorama da cultura portuguesa (Idem). A destruição dos valores da cultura indígena (Ibidem, p. 18) e o ensino dogmático e retórico voltado para a formação de quadros para a Companhia (Ibidem, p. 16) denotava o tom de alienação da cultura difundida pelos jesuítas no território nacional: uma forma cultural desprovida de senso crítico e distante dos interesses materiais e do espírito criador (Ibidem, p. 19).

Na conclusão da obra, o autor, após extensa análise das expressões culturais no período em que escreve, comentando o impacto da repressão no seio da produção cultural nacional, dedica algumas linhas para discorrer sobre a relação entre a luta pela democracia e a produção cultural brasileira. De acordo com o historiador, o "problema inicial, para a cultura brasileira, é o da retomada da liberdade; sem liberdade de pensamento e de expressão, não há condições de desenvolvimento cultural autêntico." (Ibidem, p. 135). Colocando-se o problema da cultura, para Sodré, é necessário um esforço para reconhecer as proporções da descaracterização nacional que a cultura foi submetida sob a égide da ditadura militar (Idem), restituindo-a em seus 
fundamentos nacionais (Idem) sem que isso signifique a exclusão da receptividade de outras culturais no seio da cultura brasileira (Ibidem, p. 136) e tomando em consideração o problema do uso dos meios de comunicação de massa no plano da produção cultural (Idem). Como destaca Sodré:

\begin{abstract}
De maneira alguma o problema da cultura é autônomo; antes, mais do que qualquer outro, depende de condições estruturais e conjunturais. De acordo com tais condições é que poderá ser elaborada uma política cultural em relação aos meios de massa; não poderão permanecer na situação em que se encontram (Idem).
\end{abstract}

É interessante destacar que, na análise de Arrais, problemática nos aspectos do tratamento do conceito de cultura de Sodré - chegando a acusa-lo de reproduzir uma "pérola da ortodoxia marxista" (2008, p. 392) sem necessariamente expor a adequação de tal crítica -, o panorama cultural delineado pelo historiador parece uma "viva crônica do tempo presente" (Ibidem, p. 396) (o artigo foi publicado em 2008).

\title{
Imperialismo, repressão e agonia da ditadura
}

Publicada em 1984, a obra Vida e Morte da Ditadura: 20 anos de autoritarismo no Brasil propõe-se a traçar a história da gênese do processo que culminou na tomada do poder pelos militares no ano de 1964 até o ano em que está escrevendo-a, 1983, que identifica como a "agonia da ditadura” (SODRÉ, 1984, p. 127).

Sodré introduz a obra com uma análise da peça Cabeças redondas, cabeças pontudas de Bertolt Brecht, do ano de 1935, demonstrando o obscurantismo da repressão nazista e o papel do intelectual no embate político pela "verdade" e contra a confusão semântica típica dos regimes autoritários. Um trecho da introdução elucida um pouco esta noção de engajamento:

A certa altura, Brecht assinala como tão simplesmente mostrar que tudo se transforma - e pode ser transformado, consequentemente - constitui extraordinário encorajamento e esclarecimento para os oprimidos. E com isso assusta os opressores, porque lhes anuncia $o$ fim que se aproxima. Em fases de ascensão nazista, aqueles que 
lidam com as ideias - e só por isso são suspeitos, como malfeitores - frequentemente buscam enganar a si mesmos, antes de enganar os outros, concentrando seus esforços e simulando que são profundos e heroicos, na valorização do supérfluo, do secundário, do formal. Claro está que as verdades vulgares - dois mais dois são quatro, a chuva cai de cima para baixo, e que tais - são fáceis de dizer e, além disso, fáceis de aceitar, dispensando demonstração. Mas não afetam minimamente o poder opressor, como as questões semânticas, as dúvidas formais, as polêmicas puramente éticas. É preciso - e aqui voltamos a Brecht - escolher as verdades e situálas no conjunto, isto é, na realidade dada. Escolhê-las e situá-las importa em conferir-lhes eficácia. As verdades ineficazes são inúteis (Ibidem, p. 9-10).

Em seguida, demonstra com um pouco mais de precisão a utilização desta categoria de "verdade", num sentido muito mais próximo de um materialismo do que de um idealismo vulgar:

\begin{abstract}
Nas épocas de treva, em que o nazismo, em euforia, porque tudo pode, supõe que tudo lhe é permitido, afrontando, com desprezo, crenças, convicções, direitos, como se não existissem, é realmente difícil dizer a verdade, esclarecer que não estamos divididos em cabeças redondas e cabeças pontudas, mas em opressores e oprimidos, afortunados e desafortunados, privilegiados e desprotegidos. E que não é bom para uns o que é bom para outros, nem indiferente tudo aquilo que pertence ao homem. Não há propaganda, por colorida, insistente e fantasiosa que seja, capaz de ocultar essa verdade elementar, de que as demais derivam (Ibidem, p. 10-11).
\end{abstract}

Ao longo da obra, Sodré apresenta uma análise de conjuntura dos anos 30 aos 80 que se desdobra a partir de seu primeiro capítulo, Poder Político e Poder Militar, onde há um debate teórico mais denso em que o autor discorre sobre o fundamento de sua análise: compreender o desenvolvimento histórico e social das Forças Armadas no Brasil, relacionálo com o desenvolvimento econômico e político nacional através da sua tese da revolução burguesa no Brasil, expor sua compreensão acerca dos golpes militares que marcaram a história brasileira a partir do ineditismo do movimento político de 1930 e situar o Brasil e o golpe civil-militar de 1964 num plano mais amplo de análise, considerando o fator do cenário internacional da guerra fria e debatendo o impacto da fundação da Escola Superior de Guerra, a incorporação da chamada “doutrina de segurança 
nacional” e a intervenção do imperialismo no processo de gestação do golpe.

Não sendo possível realizar aqui um estudo amplo da obra, debatendo capítulo por capítulo, o desenvolvimento da argumentação do autor e de sua análise de conjuntura - lembrando que, além de um intelectual, trata-se de um militar que chegou a uma das patentes mais altas do Exército -, cumpre aqui destacarmos alguns pontos interessantes da obra.

Trabalhando com um conceito de imperialismo não muito desenvolvido, Sodré destaca o fato de que com o início da guerra fria, marcada pela contradição entre capitalismo e socialismo, surge a chamada "doutrina de segurança nacional” (Ibidem, p. 22). Assinalando como principal elemento desta doutrina o anticomunismo - radicalizado por conta do sucesso da União das Repúblicas Socialistas Soviéticas na derrota do nazifacismo -, Sodré discute seu processo de implementação no Brasil:

Para estabelece-la e para difundi-la em cada país foram usados elementos amigos, cujos interesses ou cujas simpatias os recomendavam. Assim, a Escola Superior de Guerra, criada no Brasil no período mais quente da "guerra fria", deveria agrupar e doutrinar convenientemente os altos chefes militares das três armas, os funcionários graduados dos ministérios e instituições estatais e paraestatais e os grandes empresários. Assim doutrinados, e uniformizados na doutrinação, eles interpretariam adequada e solidariamente os acontecimentos políticos, velariam para que as bases da "guerra fria" fossem mantidas e proveriam o aparelho de Estado, em diferentes níveis e em diferentes áreas, de elementos em que se poderia confiar para a manutenção do status quo. O mais importante da doutrina estava, precisamente, no controle do aparelho militar. Se a situação apresentasse algum perigo, a solução consistiria em estabelecer governos fortes, exercidos por militares infiltrados naquela cuidadosa preparação (Ibidem, p. 24).

Expondo o desenvolvimento desta doutrina em solo nacional, Sodré discorre sobre as intervenções das Forças Armadas no campo político e atenta para o fato de que, a partir da Segunda Guerra Mundial, os golpes militares no Brasil apresentam uma alternância, ora contra a democracia, ora a favor de soluções democráticas: “tem um sentido em 1951, em 1955, em 
1961 e tem sentido oposto em 1945, em 1954, em 1964. Entre 1945 e 1965, menos de vinte anos, os militares no Brasil, depuseram quatros vezes os presidentes." (Ibidem, p. 27). Defendendo a tese que sustentou por toda sua vida, de relação entre militares e democracia no Brasil, Sodré argumenta:

\begin{abstract}
Se as forças armadas brasileiras fossem, como se chegou a afirmar, essencialmente antidemocráticas, de formação fascista, sempre a serviço dos mesmos interesses, todas as tentativas de golpes militares teriam tido o mesmo sentido - não ocorreria a alternância apontada. A alternância indica, se a análise corresponder à realidade, que as forças armadas, no Brasil, são sensíveis às pressões políticas, que elas estão subordinadas às contradições da sociedade brasileira. Desde logo, é interessante lembrar que o golpe militar de 1964 e o regime que dele se originou visou precisamente, e definitivamente, romper com aquela alternância, impedir o movimento pendular em sentido oposto. A meta fundamental das forças que acabaram por preponderar e definir o conteúdo daquele golpe e do regime foi, sem dúvida, estabelecer a posição dos militares como definitivamente oposta ao desenvolvimento econômico independente e ao desenvolvimento aqui de uma sociedade democrática. A história, já não tão breve, do referido regime, assinala, na sucessividade dos Atos Institucionais e das Constituições outorgadas, a evolução constante e progressiva para formas ditatoriais de governo, com supressão total das liberdades individuais e políticas, e com todas as concessões ao imperialismo, que passou a presidir ao crescimento econômico, dando-lhe a dimensão e o sentido (Ibidem, p. 27-28).
\end{abstract}

Ademais, discutindo o modus operandi da doutrina de segurança nacional na gestação do golpe de 1964, Sodré ressalta o fato de que, além do controle das Forças Armadas, o controle dos meios de comunicação tornou-se uma peça fundamental da ofensiva imperialista (Ibidem, p. 30).

A doutrina de segurança nacional, sendo uma "doutrina alienígena, importada, exótica, absolutamente em contradição com os valores mais altos do povo brasileiro e com os seus interesses fundamentais" (Ibidem, p. 34), tratou de estabelecer, através da Escola Superior de Guerra (ESG), uma "rede organizativa” (Idem) composta por militares e civis, como o Instituto Brasileiro de Ação Democrática (IBAD) e o Instituto de Pesquisas e Estudos Sociais (IPES), e em concordância com elementos estrangeiros (como é o 
caso da Operação Brother Sam) (Ibidem, p. 34-35). Tematizando o afastamento dos militares em relação ao povo, Sodré destaca:

\begin{abstract}
Para a ingenuidade militar brasileira, intensamente trabalhada pela propaganda, tratava-se, naturalmente, de salvar o país da anarquia. Para isso, a intervenção em força era indispensável. Assim, em defesa da Constituição, foi rasgada a Constituição; para preservar o advento de alterações democráticas, privou-se uma geração inteira do elementar direito de votar; para defender os interesses do imperialismo, vedou-se ao judiciário a apreciação dos atos ditatoriais e estabeleceu-se rígida censura que destruiu o teatro, ameaçou gravemente o cinema, calou a oposição, impediu os jornais e revistas de revelarem a verdade e estabeleceu a "ordem", isto é, o clima pantanoso do conformismo, agravado quando as prisões se encheram, o exílio se estabeleceu como norma para os adversários e, em último caso ou não, o massacre apareceu como necessidade salvadora. Houve, como é sabido, quem se propusesse ao remédio inédito: atirar dos aviões, no mar, aqueles adversários mais renitentes (Ibidem, p. 35).
\end{abstract}

Por fim, o autor aborda o processo de transição da ditadura que se ensaiava no momento da escrita da obra, discutindo a questão da anistia em relação ao enfraquecimento das bases políticas do regime e o recrudescimento da guerra fria. Neste ponto é interessante destacar que, como expõe a historiadora Lucileide Costa Cardoso, Sodré participou ativamente na Campanha da Anistia e na luta pela constituinte, figurando ao lado de vários personagens do meio intelectual no momento da fundação do Centro Brasil Democrático em 1977 (CARDOSO, 2013, p. 259-260). Esta condição não impediu que o autor realizasse uma apreciação crítica da anistia identificando seus limites, sua fragilidade e seu compasso marcado pela batuta do regime (SODRÉ, 1984, p. 122-123). O autor destaca, por exemplo, como um de seus limites, a continuidade da legislação fascista e o fato de que, com a anistia, não se criaram novas condições políticas no país; tratava-se, de certa forma, de uma continuidade do regime através de uma transição controlada e mistificada (Ibidem, p. 124-125). Nas palavras do autor:

Para as forças democráticas, a anistia era uma medida política essencial. Ela caracterizaria o próprio processo chamado de "abertura". Conforme o alcance da anistia seria a dita "abertura": uma anistia real corresponderia a uma abertura real; uma anistia mistificada daria no processo de "abertura" que realmente se 
sucedeu. Uma anistia discriminatória corresponderia a uma "abertura" discriminatória, limitada, casuística, pontilhada de violências e de repressões. E isso se verificaria, desde logo, na discriminação preliminar que pretendia, e conseguiu, tratar como criminosos políticos, para condená-los, aqueles que haviam usado a violência, e queria agora tratar como criminosos comuns aos mesmos. Punidos com o máximo rigor e considerados, para isso, como criminosos políticos, eram, com a anistia, tratados como criminosos comuns, para justificar a negação da anistia. (...) $\mathrm{O}$ regime não esquecia e nem perdoava. Pretendia fazer da anistia uma nova forma de ajuste de contas. Claro que a pacificação da família brasileira dependia da anistia, e ela não trouxe essa pacificação. $O$ processo trouxe, realmente - não a anistia - a atenuação dos antagonismos. Não foi mais possível, pelo menos na medida antiga, aplicar a tortura aos presos políticos. Mas a ameaça permaneceu clara. Quando a anistia concedida estabeleceu discriminações e marginalizou muitos de seus possíveis beneficiários, estava claro o propósito de limitar aquela pacificação. Havia que prosseguir no arbítrio, no ódio, na divisão entre os brasileiros. Para isso, a anistia teria de ser o que acabou sendo: uma concessão individual, com alcance político reduzido. Mas o regime recebeu dela benefícios e proveitos. Sua face hedionda foi retocada aqui e ali e isso contribuiu muito para que a memória dos crimes cometidos nos cárceres e nas ruas se esmaecesse como praticados em passado distante. Eles haviam sido, no entanto, uma das características essenciais do regime (Ibidem, p. 125-126).

Como destacou Célio José Losnak, o estudo de Sodré sobre a agonia da ditadura teve o mérito de antever, em 1983, "o controle que as elites conseguiriam mais tarde: o processo de abertura, articulado pelo alto, garantiu a derrota da Campanha pelas Diretas, em 1984." (LOSNAK, 20o8, p. 433).

Observamos, portanto, que não há, nesta obra, uma abordagem mais complexa sobre o impacto do autoritarismo no contexto da produção cultural no Brasil, no máximo algumas referências pontuais e genéricas. Todavia, considerando o contexto de sua publicação, é relevante a análise sodreana do processo de articulação do golpe considerando a relação das Forças Armadas com elementos estrangeiros desde a fundação da ESG.

\section{Considerações finais}


Tendo em vista a exposição realizada, cumpre aqui destacar algumas indagações que permeiam nossa abordagem da obra sodreana. As possibilidades de sua teoria da cultura brasileira, considerando suas visíveis limitações, ainda parece muito pertinente para discutir a formação e a expressão dos elementos que distinguem o que podemos chamar de cultura brasileira. Sua densa análise do autoritarismo, do desenvolvimento histórico das Forças Armadas e das intervenções estrangeiras no plano político nacional ainda apresentam vigorosa pertinência, inclusive no debate acerca do papel dos intelectuais na luta contra os desmandos das forças reacionárias. Temas contemporâneos, presentes no passado e continuamente consumidos no Brasil do século XXI. Apesar de sua obra ter sido relegada ao ostracismo, Nelson Werneck Sodré aparece ainda como relevante intérprete para discutir os problemas do Brasil

\section{REFERÊNCIAS}

ARRAIS, Cristiano Alencar. Síntese de História da Cultura Brasileira. In: SILVA, Marcos (org.). Dicionário crítico Nelson Werneck Sodré. Rio de Janeiro: UFRJ, 2008.

BASTOS, Elide Rugai; RIDENTI, Marcelo; ROLLAND, Denis. Intelectuais: sociedade e política, Brasil-França. São Paulo: Cortez, 2003.

CARDOSO, Lucileide Costa. Nelson Werneck Sodré: Censura, Repressão e Resistência. Revista Anos 9o. Porto Alegre, v. 20, n. 37, p. 237-267, jul. 2013. Disponível em: <http://seer.ufrgs.br/index.php/anos9o/article/view/28620>. Acesso em: 29 abr. 2018.

CÔRTES, Norma. O filósofo e o historiador - dois homens e um destino. In: CUNHA, Paulo Ribeiro da; CABRAL, Fátima (orgs.). Nelson Werneck Sodré: entre o sabre e a pena. 2. ed. São Paulo: UNESP, 2011. 
CUNHA, Paulo Ribeiro da. Um olhar à esquerda: a utopia tenentista da construção do pensamento marxista de Nelson Werneck Sodré. 2. ed. Rio de Janeiro: Revan, 2011.

- Nelson Werneck Sodré, os militares e a questão democrática: algumas questões e uma problemática. In: ___ CABRAL, Fátima (orgs.). Nelson Werneck Sodré: entre o sabre e a pena. 2. ed. São Paulo: UNESP, $2011 a$.

; CABRAL, Fátima (orgs.). Nelson Werneck Sodré: entre o sabre e a pena. 2. ed. São Paulo: UNESP, 2011.

CZAJKA, Rodrigo. Livros da subversão: imprensa comunista e a coleção História Nova do Brasil. Literatura e Autoritarismo, v. 7, p. 298-312, 2012. Disponível em: <http://hdl.handle.net/11449/115227>. Acesso em: 30 set. 2017.

"A hora dos intelectuais" Literatura, imprensa e engajamento no Brasil (1964-1967). Revista ECO-Pós, [S.1], v. 16, n. 2, p. 73-106, Fev. 2014. Disponível em: <https://revistas.ufrj.br/index.php/eco_pos/article/view/1185/1126>. Acesso em: 30 Set. 2017.

JACOBY, Russel. Os últimos intelectuais: a cultura americana na era da academia. São Paulo: Edusp; Trajetória Cultural, 1990.

KONDER, Leandro. Intelectuais brasileiros \& marxismo. Belo Horizonte: Oficina de Livros, 1991.

LOSNAK, Célio José. Vida e morte da ditadura. In: SILVA, Marcos (org.). Dicionário crítico Nelson Werneck Sodré. Rio de Janeiro: UFRJ, 2008.

MENDONÇA, Sueli Guadelupe de Lima. Werneck Sodré, História Nova: contribuição pioneira ao ensino de História no Brasil. In: CUNHA, Paulo 
Ribeiro da; CABRAL, Fátima (orgs.). Nelson Werneck Sodré: entre o sabre e a pena. 2. ed. São Paulo: UNESP, 2011.

NETTO, José Paulo. Nelson Werneck Sodré: o general da história e da cultura. São Paulo: Expressão Popular, 2011

Prefácio. In: SODRÉ, Nelson Werneck. O Naturalismo no Brasil. 2. ed. Belo Horizonte: Oficina de Livros, 1992

PEREIRA, Alexsandro Eugenio. Organização, estrutura e trajetória do ISEB. In: TOLEDO, Caio Navarro de (org.). Intelectuais e política no Brasil: a experiência do ISEB. Rio de Janeiro: Revan, 2005.

RIDENTI, Marcelo. Cultura e política brasileira: enterrar os anos 6o? In: BASTOS, Elide Rugai; RIDENTI, Marcelo; ROLLAND, Denis. Intelectuais: sociedade e política, Brasil-França. São Paulo: Cortez, 2003.

SILVA, Marcos (org.). Nelson Werneck Sodré na historiografia brasileira. Bauru: EDUSC; São Paulo: FAPESP, 2001.

Dicionário crítico Nelson Werneck Sodré. Rio de Janeiro: UFRJ, 2008.

SODRÉ, Nelson Werneck. Síntese de História da Cultura Brasileira. 7. ed. Rio de Janeiro: Civilização Brasileira, 1979.

. Vida e Morte da Ditadura: Vinte anos de autoritarismo no Brasil. Petrópolis: Vozes, 1984.

O Naturalismo no Brasil. 2. ed. Belo Horizonte: Oficina de Livros, 1992

; ALVES FILHO, Ivan (org.). Tudo é política: 50 anos do pensamento de Nelson Werneck Sodré em textos inéditos em livro e censurados. Rio de Janeiro: Mauad, 1998. 
TOLEDO, Caio Navarro de (org.). Intelectuais e política no Brasil: a experiência do ISEB. Rio de Janeiro: Revan, 2005.

_ Nacionalismo e ISEB em Nelson Werneck Sodré. In: SILVA, Marcos (org.). Nelson Werneck Sodré na historiografia brasileira. Bauru: EDUSC; São Paulo: FAPESP, 2001. 